\title{
Atividade dos desinfetantes cloreto de benzalcônio e iodóforo sobre cepas de Escherichia coli patogênica aviária isoladas em frangos de corte
}

\author{
Activity of the disinfectants benzalkonium chloride and iodophor on "Escherichia coli" \\ avianpathogenic strains isolated in broilers
}

\author{
CARVALHO, Daiane ${ }^{1}$; MORAES, Lucas Brunelli de ${ }^{2}$; ROCHA, Silvio Luis da Silveira ${ }^{3}$; \\ MORAES, Hamilton luiz de Souza ${ }^{4}$; SALLE, Carlos Tadeu Pippi ${ }^{4}$; AVANCINI, César \\ Augusto Marchionatti ${ }^{4^{*}}$
}

\footnotetext{
${ }^{1}$ Universidade Federal do Rio Grande do Sul, Programa de Pós-Graduação em Ciências Veterinárias, Porto Alegre, Rio Grande do Sul, Brasil.

${ }^{2}$ Instituto de Pesquisas Veterinárias Desidério Finamor, Fundação Estadual de Pesquisa Agropecuária - Saúde Animal, Eldorado do Sul, Rio Grande do Sul, Brasil.

${ }^{3}$ Universidade Federal do Rio Grande do Sul, Centro de Diagnóstico em Patologia Aviária, Porto Alegre, Rio Grande do Sul, Brasil.

${ }^{4}$ Universidade Federal do Rio Grande do Sul, Faculdade de Veterinária, Departamento de Medicina Animal, Porto Alegre, Rio Grande do Sul, Brasil.

*Endereço para correspondência: cesar.avancini@ufrgs.br
}

\section{RESUMO}

Os objetivos deste estudo foram avaliar a eficácia dos desinfetantes cloreto de benzalcônio (QAC) e iodóforo (I) sobre 10 cepas APEC (Escherichia coli patogênica aviária), bem como verificar se a característica alta patogenicidade está associada a uma maior resistência a estes compostos. O método utilizado foi $o$ de diluição através do teste qualitativo de suspensão. As variáveis estudadas foram: concentrações do QAC $(300,150,75$ e 50 ppm) e do I (100, 75, 50 e 25 ppm), tempos de contato $\left(5,10\right.$ e 20 minutos) e temperatura $\pm 20^{\circ} \mathrm{C}$. $\mathrm{O}$ QAC inativou todos os isolados nas concentrações de 300 e 150 ppm, em todos os tempos de contato, porém a 75 e $50 \mathrm{ppm}$ no tempo de 5 minutos o desinfetante não foi eficaz para uma e quatro amostras, respectivamente. O I a 100 e 75 ppm inativou os isolados em todos os tempos avaliados, mas a $50 \mathrm{ppm}$ um foi resistente e a 25 ppm oito foram resistentes em todos os tempos de exposição. A característica alta patogenicidade não pareceu promover resistência, quando comparado com a cepa padrão. Concluiu-se, nas condições do experimento, que os dois desinfetantes podem ser usados em procedimentos de higiene frente às cepas APEC, apenas levando-se em consideração a concentração de uso e o tempo de contato.

Palavras-chave: APEC, desinfetante, avicultura

\section{SUMMARY}

The objectives of this study were to evaluate the effectiveness of the disinfectant benzalkonium chloride (QAC) and iodophor (I) on 10 strains APEC (Escherichia coli pathogenic avian) and verify that the high feature pathogenicity provides protection factor against these compounds. The method used was the dilution by the qualitative suspension test. The variables studied were: the concentrations of QAC (300, 150, 75 and $50 \mathrm{ppm})$ and $\mathrm{I}(100,75,50$ and $25 \mathrm{ppm})$, contact times $(5,10$ and 20 minutes) and room temperature $\left(20^{\circ} \mathrm{C}\right)$. The QAC inactivated all strains at concentrations of 300 and $150 \mathrm{ppm}$ at all contact times, but at 75 and 50 ppm in time of 5 minutes was not effective disinfectant for one and four APEC strains, respectively. The I 100 and 75 ppm inactivated isolates in all time periods, but $50 \mathrm{ppm}$ one was tough and $25 \mathrm{ppm}$ eight were resistant in all exposure times. The highly pathogenic feature does not appear to promote resistance when compared with the standard strain. It was concluded, under the experimental conditions, the two disinfectants can be used in front of the hygiene procedures APEC strains, only taking into account the use concentration and contact time.

Keywords: APEC, disinfectant, poultry 


\section{INTRODUÇÃO}

Nas aves as amostras de Escherichia coli que possuem fatores de virulência, portanto capazes de causar enfermidade nos animais, são designadas como APEC (Avian Pathogenic Escherichia coli). Além de atuarem como agentes secundários em diversas enfermidades bacterianas e virais são responsáveis pela colibacilose aviária, a qual é considerada uma das principais doenças da avicultura industrial moderna (FERREIRA \& KNÖBL, 2009).

Visando eliminar ou reduzir a oportunidade de transmissão de patógenos como APEC, nos programas de biossegurança dos ambientes avícolas são adotados procedimentos de higiene (limpeza e desinfecção). Enquanto a limpeza refere-se a eliminação de sujidades, a desinfecção objetiva agir sobre os microrganismos em vida livre, quando no ambiente. Contudo, características intrínsecas ou adquiridas das bactérias podem impedir sua inativação por grupos químicos com ação antimicrobiana (MAILLARD \& McDONNELL, 2012).

Diversos trabalhos têm informado a resistência de APEC aos antibióticos (ABREU et al., 2010; BARBIERI, 2010; GUASTALLI, 2010; CHANSIRIPORNCHAI et al., 2011; BARROS et al., 2012; GONÇALVES et al., 2012; CUNHA, 2014). Se por um lado são frequentes estudos monitorando a resistência de microrganismos aos antibióticos, por outro a investigação da atividade dos desinfetantes sobre eles não tem acompanhado o mesmo ritmo, principalmente no contexto da saúde e da produção animal em nosso país.

Dentre os desinfetantes de grande uso na avicultura do Brasil destacam-se o cloreto de benzalcônio, do grupo dos quaternários de amônio, e o iodóforo, do grupo químico halogênios. $\mathrm{O}$ presente trabalho teve como objetivos avaliar se esses compostos químicos podem ser usados como recursos sanitários na prevenção ou controle em situações-problema de colibacilose confrontando-os com cepas APEC, bem como buscar evidências se a característica alta patogênicidade promove resistência/tolerância aos compostos testado.

\section{MATERIAL E MÉTODOS}

Foram utilizadas 10 cepas APEC isoladas em frangos de corte, oriundas de quadros de celulite e classificadas em estudo prévio como tendo alto índice de patogenicidade, em escore que incluiu também os índices de intermediária e baixa patogenicidade, ou ainda apatogênica. Neste índice, conforme trabalho de Souza et al. (2016), as cepas foram classificadas de acordo com a capacidade em causar determinado número de lesões compatíveis com colibacilose (aerosaculite, pericardite, perihepatite, peritonite e celulite), além de considerar o tempo de morte (entre um e 10 dias) e o número de pintos mortos (em grupo de 10 animais) após a inoculação subcutânea. Os isolados estavam armazenados à $-20^{\circ} \mathrm{C}$ em solução contendo $800 \mu \mathrm{L}$ de BHI (Brain Heart Infusion) e $200 \mu \mathrm{L}$ de glicerol, e para a reativação foram repicados em $10 \mathrm{~mL}$ de BHI e incubados a $37^{\circ} \mathrm{C}$ por 24 horas. Posteriormente, foram plaqueados em BEM (Eosin Methylene Blue Agar - meio seletivo para a diferenciação de bacilos entéricos).

Como referência (controle) da atividade desinfetante, utilizou-se a cepa padrão de Escherichia coli ATCC 25922.

A densidade populacional bacteriana da cultura em BHI dentro de 24 horas variaram entre $10^{8}$ e $10^{9} \mathrm{UFC} / \mathrm{mL}$.

Foram utilizados os princípios ativos puros dos desinfetantes, sendo o cloreto de benzalcônio (QAC - sinonímia cloreto de alquil dimetil benzilamónio) testado nas concentrações $300(=0,03 \%), 150,75$ e 50 ppm, e o iodóforo (I) nas de $100(=0,01 \%)$, 75,50 e $25 \mathrm{ppm}$, conforme recomendado pelo Código de Regulamentações Federais do Food and Drug Administration (FDA, 
2012). Entrevistas realizadas com médicos veterinários responsáveis pelo setor de fomento em empresa avícola e por responsáveis técnicos de matadourosfrigoríficos confirmaram a informação de serem esses desinfetantes rotineiramente usados no processo de higiene.

O método foi o de diluição com o teste o de suspensão qualitativo (BRASIL, 1993). Cada tubo de ensaio contendo $10 \mathrm{~mL}$ de uma concentração do desinfetante foi mantido a temperatura ambiente $\left( \pm 20^{\circ} \mathrm{C}\right)$ por $24 \mathrm{~h}$. Posteriormente, todos receberam $0,1 \mathrm{~mL}$ da "suspensão teste" (cultura $24 \mathrm{~h}$ entre $10^{8} \mathrm{e}$ $10{ }^{9} \mathrm{UFC} / \mathrm{mL}$ ), sendo cronometrado o tempo de contato com o desinfetante nos períodos de 5, 10 e 20 minutos. Posteriormente, foi retirado $1 \mathrm{~mL}$ do caldo em cada tempo e inoculados em triplicata em tubos de ensaio contendo $5 \mathrm{~mL}$ de BHI com neutralizador (3\% de Polisorbato $80,0,3 \%$ de Lecitina e $0,1 \%$ de Histidina).

Os tubos foram agitados, incubados a $37^{\circ} \mathrm{C}$ e observados nos períodos de 24, 48, 72 e 96 horas. Com resultados dicotômicos, os testes foram considerados como desinfetante com atividade bactericida devido ausência do crescimento bacteriano (meio de cultura sem turvação, formação de película na superfície ou de precipitado no fundo dos tubos testes) ou sem atividade devido presença de bactérias viáveis (com turvação do meio de cultura, controlando contaminação por plaqueamento em Eosin Methylene Blue Agar).

\section{RESULTADOS E DISCUSSÃO}

A cepa padrão foi inativada pelos dois desinfetantes. Apenas na menor concentração e menor tempo de contato o cloreto de benzalcônio não promoveu a inativação da cepa ATCC (Tabela 1). Com o iodóforo, a concentração de 25 ppm não foi suficiente para a sua inativação (Tabela 2).

$\mathrm{O}$ cloreto de benzalcônio provocou a inativação de todos os isolados APEC. Porém a 75 e 50 ppm o desinfetante precisou de mais de 10 min de contato para inativar um e três isolados, respectivamente. Comparando os resultados deste desinfetante frente à cepa padrão e as amostras de APEC, verifica-se que houve similaridade na atividade. A maior diferença está na concentração de $75 \mathrm{ppm}$, onde enquanto a cepa padrão foi inativada na leitura de cinco minutos, os 10 isolados APEC foram mais resistentes/tolerantes, observando-se inativação com 10 minutos de contato. $\mathrm{Na}$ concentração de 50 ppm, três isolados foram mais resistentes e precisaram mais tempo de contato do que a cepa padrão para serem inativados.

Tabela 1. Escherichia coli padrão e número de isolados Escherichia coli de alta patogêncidade - APEC - $(\mathrm{n}=10)$ inativados (sensíveis) pelo cloreto de benzalcônio em quatro concentrações e três tempos de contato, a temperatura de $\pm 20^{\circ} \mathrm{C}$

\begin{tabular}{lccccc}
\hline \multirow{2}{*}{ Item } & \multirow{2}{*}{ Tempo de contato (minutos) } & \multicolumn{4}{c}{ Concentração (ppm) } \\
\cline { 3 - 6 } Padrão (ATCC 25922) & 5 & $\mathrm{~S}$ & $\mathrm{~S}$ & $\mathrm{~S}$ & $\mathrm{R}$ \\
& 10 & $\mathrm{~S}$ & $\mathrm{~S}$ & $\mathrm{~S}$ & $\mathrm{~S}$ \\
& 20 & $\mathrm{~S}$ & $\mathrm{~S}$ & $\mathrm{~S}$ & $\mathrm{~S}$ \\
\hline \multirow{2}{*}{ APEC (n=10) } & 5 & 10 & 10 & 9 & 7 \\
& 10 & - & - & 1 & 3 \\
Não inativada & 20 & - & - & - & - \\
\hline
\end{tabular}

$\mathrm{S}=$ sensível; R: resistente. 
Tabela 2. Escherichia coli padrão e número de isolados APEC $(\mathrm{n}=10)$ inativados (sensíveis) pelo iodóforo em quatro concentrações e três tempos de contato, a temperatura de $\pm 20^{\circ} \mathrm{C}$

\begin{tabular}{lccccc}
\hline & \multirow{2}{*}{ Tempo de contato (minutos) } & \multicolumn{4}{c}{ Concentração (ppm) } \\
\cline { 3 - 6 } & 5 & 100 & 75 & 50 & 25 \\
\hline \multirow{2}{*}{ Padrão (ATCC 25922) } & 10 & $\mathrm{~S}$ & $\mathrm{~S}$ & $\mathrm{~S}$ & $\mathrm{R}$ \\
& 20 & $\mathrm{~S}$ & $\mathrm{~S}$ & $\mathrm{~S}$ & $\mathrm{R}$ \\
& 5 & $\mathrm{~S}$ & $\mathrm{~S}$ & $\mathrm{~S}$ & $\mathrm{R}$ \\
\hline \multirow{2}{*}{ APEC } & 10 & - & 10 & 5 & 2 \\
& 20 & - & - & 4 & - \\
Não inativada & - & - & - & - & - \\
\hline $\mathrm{S}=$ sensível; $\mathrm{R}=$ resistente. & & & & & \\
\hline
\end{tabular}

$\mathrm{O}$ iodóforo inativou todos os isolados APEC nas concentrações 100 e 75 ppm, porém não a 50 e $25 \mathrm{ppm}$, quando uma e oito amostras, respectivamente, foram resistentes. Comparando esse resultado com a atividade frente a cepa de referência observa-se que foi igual para as duas maiores concentrações, mas houveram isolados com suscetibilidades diferentes nas duas menores.

$\mathrm{Na}$ concentração $50 \mathrm{ppm}$, enquanto a cepa padrão foi inativada/sensível na leitura de cinco minutos, três amostras de APEC foram resistentes, sendo necessário 10 minutos de contato para serem inativadas e um isolado apresentando resistência com 20 minutos de contato.

$\mathrm{Na}$ concentração 25 ppm o resultado foi, em oito das dez cepas, igual a padrão. Porém em dois isolados ocorreu o inverso, ou seja, eles foram sensíveis ao desinfetante enquanto a padrão foi resistente. Caracterizando a comparação em percentagens de inativação, $100 \%$ dos APEC apresentaram o mesmo resultado que a cepa de referência nas duas maiores concentrações do desinfetante, $90 \%$ na terceira e $80 \%$ na quarta concentração.

Buscando referências científicas para comparar com os resultados observados nesse trabalho, em bases eletrônicas de dados (Ovid 1990 - 2015 e Web of Science - 1999 - 2016) foram encontradas apenas duas investigações que avaliaram a atividade de desinfetantes frente APEC.
Oosterik et al. (2014a) testaram a atuação de peróxiodo de hidrogênio e o composto do grupo quaternário de amônio cloreto de benzalcônio frente a 93 cepas APEC dos sorogrupos $\mathrm{O} 1, \mathrm{O} 2$ e $\mathrm{O} 78$, formadoras e não formadoras de biofilmes. Como resultado, os autores observaram que os dois desinfetantes foram capazes de inativar todas as cepas (aderidas e não aderidas) a 0,01\% (100ppm). Independente de não terem sido as cepas classificadas por sorogrupos, o resultado se assemelha aos observados no presente estudo.

Oosterik et al. (2014b) verificaram a susceptibilidade de 97 amostras APEC de galinhas poedeiras à antibióticos e desinfetantes. Os autores constataram resistência à ampicilina $(35,1 \%)$, ácido nalidíxico $(38,1 \%)$, sulfonamidas (sulfa, $41,2 \%)$ e tetraciclina $(53,6 \%)$. Os autores informaram também que as cepas não apresentaram resistência fenotípica aos desinfetantes utilizados na indústria avícola (formaldeido, glutaraldeído, peróxido de hidrogênio e composto de quaternário de amônia), indicando que não houve resistência adquirida. Esse resultado, novamente, confirma os achados do presente trabalho tendo-se, no entanto, dificuldade de comparar com exatidão os resultados da concentração da atividade bactericida posto que foram usados métodos e técnicas diferentes. Os autores consideraram com atividade bactericida o desinfetante que reduziu $99,9 \%$ da 
densidade populacional bacteriana final em relação a inicial, ao passo que o teste usado no trabalho que relatamos informa dicotomicamente inativou (bactericida) ou não inativou (não bactericida).

Não foram encontradas investigações sobre a atividade do composto iodóforo sobre cepas APEC.

Por se tratarem de cepas caracterizadas como altamente patogênicos esperava-se, como hipótese, aumento da resistência frente aos princípios antimicrobianos desinfetantes testados. No entanto, quando comparado com a cepa padrão os resultados de suscetibilidade foram similares. Carvalho et al. (2015) em estudo avaliando a relação entre cepas com a característica patogenicidade e a resistência a antibióticos, também constataram a inexistência de associação entre estas variáveis.

Concluiu-se que tanto o cloreto de benzalcônio quanto $\mathrm{o}$ iodóforo foram capazes de inativar todos os isolados APEC, podendo ser empregados nos procedimentos de desinfecção. As variáveis concentração e tempo de contato interferem na atuação destes compostos, devendo ser levados em consideração quando no estabelecimento e monitoramento dos protocolos de higiene.

\section{REFERÊNCIAS}

ABREU, D.L.C.; FRANCO, R.M.; NASCIMENTO, E.R.; PERERIRA, V.L.A.; ALVES, F.M.X.; ALMEIDA, J.F. Perfil de sensibilidade antimicrobiana e detecção do gene ISS pela reação em cadeia da polimerase na tipificação de Escherichia coli patogênica em codornas de corte sob inspeção. Pesquisa

Veterinária Brasileira, v.30, n.5, p.406410, 2010.
BARBIERI, N.L. Resistência a antibióticos, prevalência dos fatores associados à virulência, tipagem filogenética e perfil filogenético de isolados de Escherichia coli patogênica aviária (APEC). 2010. 113f. Dissertação (Mestrado) - Universidade Federal do Rio Grande do Sul, Porto Alegre.

BARROS, M.R.; SILVEIRA, W.D.; ARAÚJO, J.M.; COSTA, E.P.; OLIVEIRA, A.A.F.; ANA PAULA DA S.F. SANTOS, A.P.S.F. ; SILVA, V.A.S.; MOTA, R.A. Resistência antimicrobiana e peril plasmidial de Escherichia coli isolada de frangos de corte e poedeiras comerciais no Estado de Pernambuco. Pesquisa Veterinária Brasileira, v.32, n.5, p.405-410, 2012.

BRASIL, Ministério da Agricultura Pecuária e Abastecimento. Portaria 101, de 11 de agosto de 1993. Aprova e oficializa os métodos analíticos para controle de produtos de origem animal e seus ingredientes, 1993.

Diário Oficial da União, de 17 de agosto de 1993. Seção 1, p.11937.

\section{CHANSIRIPORNCHAI, N.;} MOOLJUNTEE, S.; BOONKHUM, P. Antimicrobial sensitivity of Avian pathogenic Escherichia coli (APEC) isolated from chickens during 2007-2010. Journal of Veterinary Medicine, v. 41, n.4, p.519-522, 2011.

CARVALHO, D.; FINKLER, F.; GRASSOTTI, T.T.; KUNERT FILHO, H.C.; LIMA, F.E.S.; SOARES, B.D.; ROSSATO, J.M.; CUNHA, A.C.; BRITO, K.C.T.; BRITO, B.G. Antimicrobial susceptibility and pathogenicity of Escherichia coli strains of environmental origin. Ciência Rural, v.45, n.7, p.12491255, 2015.

CUNHA, M.P.V. Resistência aos antimicrobianos e virulência de Escherichia coli patogênica para aves (APEC) isoladas de perus com doença respiratória. 2014. 111f. Dissertação (Mestrado) - Universidade de São Paulo, São Paulo. 
FERREIRA, T. Z., SESTERHENN, R., KINDLEIN, L. Perdas econômicas das principais causas de condenações de carcaças de frangos de corte em Matadouros-Frigoríficos sob Inspeção Federal no Rio Grande do Sul, Brasil. Acta Scientiae Veterinariae, v.40, n.1, 1021, 2012.

FOOD AND GRUG ADMINISTRATION. Food and Drugs. Departamento f Health and Human Services, Part 178 Indirect Food Additives: Adjuvants, Producers AIDS and Sanitizers. Code of Federal Regulation.

Title 21. v. 3, April - 2012.

GONÇALVES, M.R.; PEREIRA, V.L.A.; SILVA, R.C.F.; OLIVEIRA, L.A.T.; NASCIMENTO, E.R. Perfil de resistência antimicrobiana de isolados de Escherichia coli positiva para gene iss em frangos de corte na idade de abate. Enciclopédia Biosfera, v.8, n.15, p.1288, 2012.

GUASTALLI, E.A.L. Estudo dos fatores de virulência, sorogrupos, patogenicidade e susceptibilidade antimicrobiana das cepas de Escherichia coli isoladas de pintainhas de reposição de postura. 2010. Dissertação (Mestrado) - Universidade Estadual Paulista, Jaboticabal.

JAENISCH, F.R.F.; COLDEBELLA.A.; MACHADO, H.G.P.; ABREU, P.G.; ABREU, V.M.N.; SANTIAGO, V. Importância da higienização na produção avícola. Embrapa - Ministério da Agricultura Pecuária e Abastecimento. Comunicado Técnico, n. 363, p.1-5, 2004.

MAILLARD, J.Y.; MCDONNELL, G. Selection and use of disinfectants. In Practice, v.34, n.4, p.292-299, 2012.

OOSTERIK, L.H.; TUNTUFYE, H.N.; BUTAYE,P.; GODDEERIS, B.M. Effect of serogroup, surface material and disinfectant on biofilm formation by avian pathogenic Escherichia coli. The Veterinary Journal, v.202, n.3, p. 561-565, 2014a.
OOSTERIK, L.H; PEETERS, L.; MUTUKU, I; BRUNO M. GODDEERIS, B.M.; BUTAYE, P. Susceptibility of Avian Pathogenic Escherichia coli from Laying Hens in Belgium to Antibiotics and Disinfectants and Integron Prevalence Avian Diseases, v.58, n.2, p.271-278, 2014b.

SOUZA, G.F.; ROCHA, S.L.S.; FURIAN, T.Q.; BORGES, K.A.; SALLE, F.O.; MORAES, L.B.; MORAES, H.L.S.; SALLE, C.T.P. Classification of Avian Pathogenic Escherichia coli by a Novel Pathogenicity Index Based on an Animal Model. Acta Scientiae Veterinariae, v.44, p.1-6, 2016.

Data de recebimento: 27/06/2016

Data de aprovação: 11/01/2017 